\title{
Pesquisa Fenomenológica em Educação: Possibilidades e desafios
}

\author{
Maria Aparecida Viggiani Bicudo \\ mariabicudo@gmail.com \\ https://orcid.org/0000-0002-3533-169X \\ Universidade Estadual Paulista - UNESP, Câmpus de Rio Claro \\ São Paulo, Brasil.
}

Recibido: 17/05/2020 Aceptado: 19/05/2020:

\section{Resumen:}

Este texto se configura más como un ensayo en relación con un tema, que como un artículo científico académico. En él son tratadas dos cuestiones de fondo relativas a la investigación fenomenológica en educación, destacándose la propia fenomenología, la educación y la investigación. De la fenomenología, se exponen comprensiones acerca de los siguientes asuntos: lo dado, la subjetividad, la intersubjetividad, y la objetividad, que son temas que se entrelazan cuando se busca comprender la educación y la investigación desde el abordaje fenomenológico. Además, también fue explicitado el entendimiento de la educación que subyace en sus procedimientos de pesquisa. Entre éstos se destaca la importancia de la descripción y los posibles modos de registrarla y analizarla.

Palabras clave: Fenomenología, Educación, Investigación.

\section{Pesquisa fenomenológica em educação: possibilidades e desafios}

\section{Resumo}

Este texto se configura mais como um ensaio a respeito do tema, do que como um artigo científico-acadêmico. Trata das questões de fundo que envolvem a pesquisa fenomenológica em educação, destacando a própria fenomenologia, a educação e a pesquisa. Da fenomenologia, expõe compreensões sobre o dado, percepção, subjetividade, intersubjetividade, objetividade temas que se entrelaçam quando se busca compreender educação e pesquisa nessa abordagem. Foi explicitado o entendimento de educação que subjaz os procedimentos de pesquisa. Sobre estes foi destacada a importância da descrição e modos possíveis de registrá-la e de analisá-la. Palavras-chave: Fenomenologia, Educação, Pesquisa.

\section{Phenomenological research in education: possibilities and challenges}

\begin{abstract}
.
This text is configured more as an essay on the theme, than as a scientific-academic article. It deals with important issues involving phenomenological research in education, highlighting phenomenology itself, education and research. From phenomenology, understandings on givenness, perception, subjectivity, intersubjectivity, objectivity are exposed. These are themes that intertwine with those of education and research assumed in this approach. The understanding of education that underlies research procedures was made explicit. Regarding these, the importance of description and possibible ways of recording and analysing it were hightlighted.

Key-words: phenomenologuy; education; research.
\end{abstract}




\section{Introdução}

É importante afirmar que a fenomenologia tratada neste artigo, já, no início, diz respeito à fenomenologia husserliana, introduzida por Edmund Husserl (1859 - 1938), avançando com seus discípulos e seguidores. Portanto, ao mencionar fenomenologia e pesquisa fenomenológica estarei referindo-me a essa corrente filosófica. Importante, também explicitar que este texto se configura mais como um ensaio a respeito do tema, sugerido pelo editor da Revista, do que como um artigo científico-acadêmico.

A pesquisa fenomenológica em educação abrange um amplo leque de temas importantes para sua compreensão. Destacarei dois deles que convergem para o título do artigo: Fenomenologia e Educação e, em seguida, trabalharei a questão da Pesquisa.

\section{FENOMENOLOGIA}

A fenomenologia husserliana busca compreender sempre o modo pelo qual o conhecimento do mundo é constituído. Não se trata de explicitar a constituição do mundo, mas tão somente do conhecimento que nós, seres humanos, produzimos ao habitá-lo. É entendida como uma corrente filosófica. Como tal, seu modo de proceder é filosófico, estando voltada para os assuntos recorrentes à filosofia ocidental desde seu nascimento, na Grécia, no século VIII a.C. Busca investigar o real e a realidade; o conhecimento da "verdade", o valor e, ao caminhar por essas investigações, levanta o questionamento maior: quem é esse ser que pergunta pelo real, pela verdade, pelo valor, por si mesmo; portanto, quem é o homem? Nesses vinte e oito séculos de história, muitos pensadores e respectivas escolas focaram essas perguntas e as responderam diferentemente.

Nasce com Edmund Husserl, matemático que, desde o início, põe-se a interrogar sobre o objeto matemático e o modo de seu conhecimento ser constituído e produzido, passando a galgar status de realidade objetiva que perdura histórica e culturalmente atravessando épocas. Esse autor escreve o seu trabalho de doutorado em 1887, denominado "Sobre o conceito de número" (Über den Begriff der Zahl), cujos estudos embasam sua primeira obra importante, Filosofia da Aritmética, datada de 1891 (Philosophie der Arithmetik ). Nesse trabalho, está preocupado com a origem da aritmética, já entendendo "origem"1 como o

\footnotetext{
${ }^{1}$ A origem se presentifica, nessa obra, como um estar lá original, que emerge no ato intuitivo confiado à subjetividade de um sujeito.
} 
momento primeiro de sua constituição na subjetividade do sujeito e não, por exemplo, como uma origem cronológica que encadearia fatos históricos. Entretanto, as argumentações que tece, nessa investigação, são de natureza psicológica, seguindo os ensinamentos de Franz Brentano, seu professor de psicologia e de filosofia, que já trabalha a intencionalidade da consciência.

Matematicamente, foi orientado por Karl Weierstrass, importante matemático alemão, que ensina na Universidade de Berlim. Esse seu trabalho foi muito criticado pelos matemáticos, em decorrência de ele colocar, na psicologia, as explicações para os fundamentos da lógica. Essas críticas pesaram e ele avançou com sua interrogação pelo caminho de restaurar a "lógica pura" e conferir rigor à filosofia fenomenológica. Nos anos de 1900/1, publica o primeiro volume de "Investigações Lógicas", sob o título de "Prolegomena". Nessa obra, ele lança sua crítica ao psicologismo e ao historicismo, tomando-os no âmbito da ciência factual, bem como já vai tecendo suas críticas à ciência positivista, que é imperante nos meios científicos e acadêmicos da época. Essas críticas e os modos de respondê-las habitam o mote propulsor de suas investigações ao longo de sua vida. Eu, particularmente, encontro no livro "Crise das ciências europeias contemporâneas" (2008) e no apêndice desse livro, “A origem da Geometria" (2008), a articulação do seu pensar a respeito dessas críticas e a explicitação do modo pelo qual entende a realidade do Mundo-Vida (Lebenswelt), a psicologia e a história.

De 1887 a 1938, dedica-se a pensar sobre a “exatidão" das ciências exatas e sua produção que tem como solo o Mundo-Vida (Lebenswelt), ou seja, a realidade mundana e que não advém da criação de uma consciência fechada em si ou de um mundo outro que não esse humano, como é o caso do mundo das Ideias platônicas. Implícito ao seu pensar questionador, está sua crítica ao positivismo. Porém, a investigação que realiza não é linear, mas adentra por meandros e atalhos que conduzem a pensamentos cada vez mais entrelaçados uns nos outros, cuja clareza não se faz de imediato e, quando se faz, tende a se obscurecer em seguida.

De modo que pretendo seja didático, trarei um esquema da complexidade de suas investigações que, ao longo de sua vida acadêmica, também contaram com a presença de muitos 
alunos como Martin Heidegger ${ }^{2}$ e Edith Stein $^{3}$.

Husserl busca saber da constituição do objeto matemático e do modo pelo qual esse objeto permanece inteligível em sua objetualidade ao longo da história de povos e culturas. Se ele critica a filosofia positivista, então não busca uma verdade (teórica, por exemplo) para embasar suas articulações. É conhecida a afirmação de Husserl "ir às coisas, elas mesmas", sem intermediação de conceitos que digam o que são. Então, de onde partir? Há o dado. No caso aqui considerado, o objeto matemático, tomado como "a coisa ela mesma, a ser compreendida". Como dele (objeto matemático) compreender sua constituição? Foi preciso adentrar por questões sobre o dado e como isso, o dado, é dado; é dado a quem e como é dado; o dado, em si, é o real? É a verdade? Como compreender "verdade"?

Note-se que, ao começarmos a puxar os fios, entrelaçados no tecido em que o "dado" (aqui tomado como um exemplo) está tecido, outras questões vão se pondo. E ele não se negou a enfrentá-las. Inclusive, desde as Investigações Lógicas, coloca sob seu olhar indagador o próprio método de investigar. De maneira um tanto ingênua, ouve-se falar em método fenomenológico, como se fosse um método que definisse como proceder, seguindo o exemplo do método positivista. Mas o método fenomenológico foi motivo de constantes retomadas pelo próprio Husserl, cujo modo de ser sempre descontente com o já clareado, via ali regiões obscuras. Portanto, não há um método fenomenológico, mas há procedimentos pautados na filosofia fenomenológica explicitada, enquanto uma atitude assumida como um modo de ser e de pesquisar.

Desse modo, nos trabalhos de Husserl, há sempre a "démarche" da descrição do compreendido e questionamentos sobre o método.

A seguir, destacarei os temas, iniciando por um e puxando com ele o fio da teia dessa complexidade.

\footnotetext{
${ }^{2}$ Martin Heidegger (Meßkirch, 26 de setembro de 1889 - Friburgo em Brisgóvia, 26 de maio de 1976) foi um filósofo, escritor, professor universitário e reitor alemão. Foi um pensador seminal na tradição continental e hermenêutica filosófica, e é "amplamente reconhecido como um dos filósofos mais originais e importantes do século XX." É mais conhecido por suas contribuições para a fenomenologia e existencialismo, embora, como a Enciclopédia de Stanford de Filosofia adverte, "seu pensamento deve ser identificado como parte de tais movimentos filosóficos apenas com extremo cuidado e qualificação"., (WIKEPEDIA, 06/05/2020; 19H59 min., horário de Brasília Brasil)

${ }^{3}$ Edith Theresa Hedwig Stein, canonizada como Santa Teresa Benedita da Cruz (Breslávia, 12 de outubro de 1891 - Oświęcim, 9 de agosto de 1942), foi uma filósofa e teóloga alemã. Foi a segunda mulher a defender uma tese de doutorado em filosofia na Alemanha, tendo sido discípula e depois assistente de Edmund Husserl, o fundador da fenomenologia ${ }^{[1]}$ Já religiosa, anotou: "A fé está mais próxima da sabedoria divina do que toda ciência filosófica e mesmo teológica". (WIKEPEDIA, 06/05/2020; 20h02 min., horário de Brasília Brasil).
} 


\section{Destacando alguns temas}

\section{O dado}

Pensemos no "dado". No cotidiano das pesquisas realizadas nas academias, por exemplo, fala-se: coletei os dados; obtive os dados; analisei os dados. E esse modo de falar passa sem questionamento, aceita-se, de maneira naturalizada, que o pesquisador obteve os dados, etc. Mas, o que é o dado? Ele está ali para ser obtido, pego, manipulado?

Perguntamos: o que nos é dado a conhecer e como isso nos é dado? Em campos filosóficos, aprofundando sobre o que é dado, fala-se da "coisa". O que é a "coisa"? As perguntas vão se encadeando, revelando que, para nós humanos, não há um fim ou um começo. Heidegger (1992), por exemplo, tem um livro intitulado “Que é uma coisa?”, citado aqui para evidenciar a complexidade dessa pergunta.

Vamos focar o "dado". Do que se trata? Do objeto? Mas objeto já é uma construção epistemológica descrita pela ciência, que o define. Na visão positivista, e não apenas, é visto como sendo objetivo e separado do sujeito. Para ser uma construção, é preciso uma materialidade que viabilize a construção. Objeto é uma denominação muito ampla, podendo ser aplicado ao que quer que se seja, como realidades históricas, psicológicas, físicas, matemáticas... e por aí vai.

A fenomenologia entende o dado como o que chega ao sujeito que, de modo atento, olha para algo querendo saber do se trata. Esse algo poderia ser visto como a "coisa", que nos escapa ao conhecimento, mas que se doa aos nossos sentidos, em seus modos de doação. Na língua inglesa, fala-se em "givenness". Em português, não encontro uma palavra que me pareça traduzir, fidedignamente, esse sentido. Poderia ser "dadidade". A coisa é o fenomenal. O fenomenal se faz sentir nas sensações pontuais na carnalidade do corpo-encarnado ${ }^{4}$ e em cuja dinamicidade vai se entrelaçando de maneira que indícios da coisa vão se configurando ${ }^{5}$. Quando o sujeito se dirige de modo intencional ao que está solicitando sua atenção, o fenomenal a ele se mostra como "fenômeno", percebido então como uma totalidade que se destaca de um fundo, o solo mundano em que se situa.

Husserl (Idee, 2002) explicita o movimento de constituição do conhecimento pelo

\footnotetext{
${ }^{4}$ Corpo-encarnado, corpo-vivente e corpo-próprio explicitam uma mesma ideia a ser exposta no item sobre percepção.

5 O tratamento que Husserl dá ao "sentido" é interpretado por muitos autores como uma atitude empiricista, uma vez que, o empiricamente dado aos sentidos, seria a base da construção do conhecimento.
} 
entrelaçamento dos sentidos, experienciados no corpo-próprio ou corpo-encarnado, pelos diferentes órgãos dos sentidos, como audição, tato, visão, paladar, olfato e um sexto, cinestesia (movimento sentido), que vão se amalgamando e possibilitando a percepção de um objeto e sua forma em termos de figura e fundo, o qual se presentifica no fluxo da consciência. Ao focar conhecimento, o seu correlato é solicitado: a realidade. Esta é vista como um correlato objetual dos atos da consciência.

A consciência não é entendida como um órgão específico, nem como recipiente em que estão crenças e juízos a respeito do certo e do errado; do bem e do mal. Também não uma forma que imprime à experiência formas de organização. Ela, na fenomenologia, é entendida como o que nos permite sempre nos darmos conta, de modo íntimo, dos atos que realizamos. Para mim, é muito esclarecedora a seguinte exposição de Ales Bello:

Nós nos damos conta do sentido de viver, pois damo-nos conta de viver pelo sentido do corpo vivo. Santo Agostinho dizia uma frase muito bonita: intima scientia est qua nos vivere scimus que significa que no interior, nós seres humanos, sabemos, temos consciência que vivemos. E o que é essa ciência íntima? É a consciência (Ales Bello, 2016, p. 88).

Estar consciente não quer dizer que, a todo o momento, estejamos refletindo sobre nossos atos. Apenas diz que percebemos, ou seja, sabemos que estamos agindo. A consciência sempre está lá, nos atos que realizamos. É um movimento intencional mantido na intencionalidade. Esta é um conceito nuclear da fenomenologia. É complexo e difícil de explicá-lo. Mas, conforme entendo, pode ser compreendido a um primeiro olhar como um fio invisível que nos contata às coisas e as traz à consciência como percebidas.

Nos parágrafos anteriores, de maneira rápida, introduzi “fenômeno". Imagino que muitas pessoas avessas à fenomenologia já não suportam ler e ouvir sobre o significado de fenômeno e de fenomenologia. A elas, peço desculpas, mas é preciso falar também para os que pela primeira vez ouvem esses termos. "Fenômeno" é o que se mostra no ato de perceber ou de intuir. É correlato a quem percebe ou intui. Este que percebe ou intui realiza esses atos de acordo com suas especificidades. Por exemplo, uma pessoa que não distingue cores, não pode intuir a vermelhidão do vermelho; ou uma pessoa que não sente sensações táteis, não pode sentir a frialdade do gelo. Por seu lado, o fenômeno se doa em seus modos de doação. Naquilo que ele $e^{6}$ : na sua dureza, frialdade, luminosidade, etc. "Fenomenologia" é uma palavra composta por

\footnotetext{
6 “Aquilo que ele é" é um dos modos pelos quais Husserl entende "essência".
} 
"fenômeno" mais "logos". "Logos" entendido como articulação inteligível realizada pelo pensar. Pensar, entretanto, não é um ato vazio (abstrato) sem materialidade. Porém, se efetua também com o que se mostrou na percepção que, por sua vez, é correlato ao sujeito e com ele está no Mundo-Vida?

Compreendendo o significado de fenômeno, percebemos que nunca conhecemos o que há em si, o real entendido como objetivamente dado. De modo apressado, o leitor poderá dizer: mas isso é já era dito por Kant, por exemplo. Onde está a novidade? O novo está no modo pelo qual "a coisa" é dada ao sujeito intencional: como fenômeno e este não existe de modo objetivamente dado. Revela-se apenas na sensação (na fisicalidade do corpo-vivente) e na percepção do percebido ${ }^{8}$.

Para a fenomenologia, sempre compreendemos de modo original, isto é, na imediaticidade do ato perceptivo, o que nos é dado no ato de perceber. O entendimento do que diz esse modo de compreender é importante, pois expressa a atitude fenomenológica9 ${ }^{9}$, que é exposta de modo pleno nas Meditações Cartesianas. Diz que a coisa: “a) não está além de sua manifestação e, portanto, ela é dependente da consciência; b) a consciência não é parte ou região de um campo mais amplo, mas é ela mesma um todo absoluto não dependente e que nada tem fora de si. (Moura, 1989, p. 170).

Essas duas afirmações têm sido alvo de muitas críticas, uma vez que leitores menos dispostos a se aprofundarem nas articulações que delas avançam, tomam-nas como dizendo que a percepção é entendida como conhecimento na linha fenomenológica. Conforme raciocinam, trata-se de um conhecimento tão somente do sujeito, portanto subjetivista e relativo. Junto a essa crítica também está o entendimento desvirtuado de que o mundo ou as coisas que estão no mundo são criados pela consciência. Grosso modo, poderia ser compreendido, seguindo esse raciocínio, que o sujeito (o Eu cartesiano) cria a realidade.

No entanto, não é assim. A compreensão da constituição e da produção do conhecimento, conforme a filosofia fenomenológica husserliana expõe, exige que o estudioso se decida escavar

\footnotetext{
${ }^{7}$ Mundo-Vida, traduzido da palavra alemã Lebenswelt, é entendido como a realidade constituída e produzida no movimento histórico cultural, que traz consigo o presente, o passado e o futuro em sua temporalidade. Não é um recipiente em que são colocadas as coisas e os seres mundanos, como conhecimento, teorias, etc. É o solo histórico e cultural em que habitamos.

${ }^{8}$ Sobre percepção, falaremos no item específico.

${ }^{9}$ Outra atitude descrita por Husserl é a natural. Diz da "concepção das coisas do mundo natural (ou seja, não questionado, mas tomado em sua objetividade - explicação da autora), concebidas como conteúdos positivos, pensáveis como distintos, por princípio dos fenômenos ou manifestações”. (Moura, 1989, p. 164).
} 
o terreno complexo em que a articulação das noções entrelaçadas se aprofunda. Tendo em vista que este é um artigo e, portanto, não se espera que se torne um tratado sobre essa filosofia ${ }^{10}$, apresento, até onde possível for, um panorama das ideias que entendo como importantes e mesmo nucleares para se visualizar sua complexidade. Falei do "dado" e que é dado nas sensações e nas percepções do corpo-vivente.

\section{Percepção}

A percepção é um ato do sujeito. De modo geral, fala-se em sujeito como se fosse um objeto naturalizado e que, a priori, sem questionamentos, já se sabe do que se fala. É entendido, comumente, como aquele que pratica uma ação, alguém a quem nos referimos ou que sofre uma ação.

Apenas para problematizar a questão, peço que fiquemos atentos às diferentes possibilidades de compreender sujeito. Na linguagem proposicional, o sujeito é quem dita as ações dos verbos. Entretanto, no âmbito da filosofia, há o sujeito ontológico, o sujeito do conhecimento, o sujeito moral, o sujeito social. O sujeito não é abstrato. É ator de uma ação ou a quem nos referimos como tendo realizado algo, por exemplo. Ou também pode ser entendido como uma construção social ou psicossocial. O sujeito age, se ex-põe. O "ex" expressa o movimento de dentro para fora; neste caso, põe para fora seu modo de mostrar-se. Mas se o sujeito não é abstrato, então o que se mostra? O que vejo primeiro ou sinto primeiro, antes de qualquer construção ou entendimento de quem age?

No mundo presencial, entendendo-o em sua fisicalidade ${ }^{11}$, o corpo-encarnado, também entendido como corpo-próprio ou como Husserl o denomina, corpo-vivente (Leib), dá-se a conhecer em sua carnalidade e na ex-posição de suas compreensões que se evidenciam em suas ações intencionais.

Para explicitar o sentido de percepção nessa abordagem filosófica, conforme compreendo, é preciso “escavar” o entendimento de corpo-vivente.

É entendido como uma totalidade carnal. Aqui é importante fazer uma distinção entre a concepção de carnal (embodied) como presente em estudos da ciência neurológica e a

\footnotetext{
${ }^{10}$ Também não sei se eu, com o pouco que sei de fenomenologia husserliana, daria conta de uma tarefa como essa.

${ }^{11}$ Estou colocando essa consideração porque, quando nos locomovemos na realidade do ciberespaço, o sujeito (do outro) é percebido na dimensão das especificidades dessa realidade. Para tanto, vários trabalhos podem ser encontrados em www.mariabicudo.com.br
} 
carnalidade como exposta na fenomenologia. Nas ciências neurológicas, o corpo (Körper) é uma totalidade composta por mente $($ mind $)$ e todo o intrincado organismo neurofisiológico que faz ou executa ações. A mente é o órgão de comando central, explicado em sua funcionalidade neurológica. Na fenomenologia, o corpo-próprio (Leib) é constituído por dimensões físicas, psíquicas e espirituais. A dimensão física diz do organismo, de sua estrutura (inclusive neurológica) e de sua funcionalidade, seus modos de sentir sensações; a do psíquico diz das emoções e de aspectos da cognição; a dimensão do espiritual, diz das ações de julgar. Essa totalidade é motriz e seus movimentos são intencionais ${ }^{12}$, portanto um dos sentidos do corpovivente é o kinestésico, ou seja, ele se movimenta sempre em direção a algo que o mantém atento. Estar intencionalmente "voltado para" é a característica de estar-se consciente. E, por isso, em fenomenologia, fala-se em consciência. Esse corpo-vivente faz, age e tem ciência que está fazendo e agindo. Ele se sabe vivendo.

Entendo que estar ciente do que se faz evidencia o perceber-se fazendo, explicitado por Husserl como vivência (Erlebiness). De modo ingênuo, ou seja, sem questionamento, pode-se entender "vivência" como experiência. E, no âmbito desse entendimento, pode-se perguntar: e daí? Tantos filósofos e tantas teorias da psicologia trabalham com experiência e, inclusive alguns, como Bondía (2002), referem-se à experiência como algo que nos passa e que nos toca, de maneira a deixar marcas em nosso modo de ser. Destaco, entretanto, que "vivência" flui enquanto seu movimento dura na temporalidade. A cada momento, vive-se o presente da ação que desliza para o já foi, chamando para o "agora" o que está no fluxo do horizonte dessa ação que está sendo realizada. ${ }^{13}$ Sabemos que estamos vivendo, porém só nos damos conta do que estamos vivenciando em um ato reflexivo. Este é um ato da consciência. "Esse é o movimento reflexivo, pelo qual a consciência abarca as vivências, permitindo-se lucidez. Interessantemente, o verbo grego phainomai também significa brilhar, luzir. 'Estar lúcido' significa ver com lucidez, com clareza" (Bicudo, 1999, p. 19).

Essa clareza ocorre, no agora, no momento da percepção. Perceber é um ato da consciência que, em sua imediatez; ou seja, no momento em que ocorre, expõe, de modo claro, a essência do visto. Por isso, é entendida como primado do conhecimento. O claramente visto

\footnotetext{
12 Intencionais não tem o sentido de proposital, ou seja, não corresponde a um propósito. Refere-se à intencionalidade da consciência.

${ }^{13}$ Sobre a duração dos atos e de sua ocorrência no presente, indico a leitura da tese de Tais Barbariz (2017) e de Bicudo, M.A.V. (2020).
} 
escorrega no fluxo da consciência e se torna obscuro. Portanto, demanda pelos atos da consciência (comparar, imaginar, fantasiar, julgar, articular, refletir, expressar, articular e outros) para avançar na constituição do conhecimento. Como acima mencionado, o agora é um instante sempre a deslizar para o "já-foi”, abarcado na corrente da lembrança. Portanto, a clareza do fenômeno percebido se torna opaca. A percepção se dá no agora e este é um momento em que se compreende o que se vê, sem intermediação do símbolo (Derrida, 1994). Isso significa que a linguagem é intermediária, colocando-se entre o percebido, na vivência, de modo imediato e a expressão do percebido. Compreendo que a clareza do fenômeno, percebido de modo claro no ato de perceber, torna-se, nesse movimento, obscurecido duplamente: no movimento em que o agora vai se deslizando para o "já-foi” e por ser falado ou expresso pela palavra.

É importante destacar que o ato de perceber se dá na subjetividade do sujeito, donde a percepção clara do fenômeno ocorre na vivência do corpo-vivente. Além disso, o percebido é enlaçado pela intencionalidade, de modo que a consciência realize os atos cognitivos, articulando o que assim lhe é trazido. Essa ação articuladora também se dá na subjetividade do sujeito. Porém o ato de expressar enlaça aspectos não só do sujeito, uma vez que solicita também a materialidade da expressão: a linguagem.

Compreender o ato da percepção é vital para que se compreenda o pensar fenomenológico. Eu - sujeito, corpo-vivente - percebo "a coisa". Mas a coisa não é, objetivamente, dada na apreensão intelectual. Há sensações sentidas no e pelo corpo-vivente e que lhe chegam pelos órgãos dos sentidos: tato, visão, olfato, paladar, audição. Sensações essas que se entrelaçam no dinamismo e na funcionalidade do organismo vivo e vão configurando indícios da coisa (do fenomenal) que assim lhe chega. Husserl (Ideas, 2002) se refere a essas sensações como experiências concretas por se tratar de afetações sensórias. Elas contribuem com o preenchimento de sentido do percebido. Sendo assim, o percebido evidencia uma dimensão que transcende a subjetividade do sujeito, na medida em que enlaça os indícios do fenomenal e da coisa percebida. Concomitantemente, a ação articuladora da consciência avança de maneira que a inteligibilidade disso que está sendo articulado vai se tornando clara Ao mesmo tempo é solicitada e vem ao encontro dessa organização articuladora a linguagem e sua estrutura. Estou dizendo, então, que os atos subjetivos não são tão somente subjetivos, uma vez que enlaçam o percebido, situado no mundo-vida e a linguagem comunicada no mundo-vida.

É pela expressão do compreendido que o sujeito se ex-põe; dá-se ao autoconhecimento, 
bem como se dá ao conhecimento do outro. Expressão que abrange toda a dimensão da linguagem humana: do corpo-vivente, pelos gestos e respectivos movimentos intencionais (kinestésicos) que evidenciam a direção da ação, pela fala de palavras carregadas de sentidos e significados histórico-culturais, pela estrutura gramatical da língua de um povo, por desenhos, rituais e por ai vai.

Com essas colocações, estou realizando o movimento de transcender a esfera da subjetividade, adentrando a da intersubjetividade, em que o outro está presente.

\section{Intersubjetividade}

O âmago da constituição da intersubjetividade se encontra na compreensão de como “o outro" se constitui para o ego. O outro, o alheio, "é um problema filosófico fundamental por si só e concerne à relação entre minha consciência do corpo e do comportamento do outro e minha consciência dos estados psicológicos dele/a." (Bell, p. 219, 1990). No âmbito da filosofia fenomenológica, essa é uma questão crucial para que se ultrapasse o impasse do solipsismo do ego transcendental, tão criticado nos primeiros trabalhos desse autor.

Na Quinta Meditação, Husserl afirma a importância de se desenvolver um trabalho sistemático que possibilite uma visão

sobre a intencionalidade explícita e implícita em que, a partir do terreno do nosso ego transcendental, o alter-ego se anuncia e se confirma sobre como e em que intencionalidades, em que sínteses, em que motivações o sentido alter-ego se forma em mim e, sob o título de experiência concordante do que me é alheio (Fremd) se confirma como sendo e estando, ao seu modo, ele próprio aí (Husserl, s/d, p. 132).

Como o sentido do outro se forma em mim? Essa é uma questão crucial, na medida em que somos, em cada caso, corpo-encarnado, síntese espaço-temporal e de movimento intencional, totalidade única. Como o sujeito, corpo-vivente, toma conhecimento da vivência do alheio? Não se afastando do seu método de estudo, é importante destacar que Husserl pergunta “como o sentido do outro se forma em mim?". Entendo que em outros estudos husserlianos a mesma pergunta é endereçada à comunidade, à constituição do grupo social, da sociedade, do Estado. Afasta-se, na busca dessa compreensão, das teorias explicativas da sociologia, da psicologia social e de outras correntes filosóficas que tomam a sociedade como naturalmente estando aí, de modo objetivamente dado, e nela o alter-ego, o outro, em que o alheio se instala em mim pelas relações sociais. 
Fenomenologicamente, entende-se que é preciso que eu me perceba "ego" e ao outro, "alter-ego", dando sustentação existencial às relações sociais. Eu, sujeito corpo- encarnado, tenho experiência do mundo que me é alheio e o percebo nas ações que realizo, nas minhas sensações táteis, visuais e outras, bem como na cinestesia implícita ao eu faço, eu ando, eu posso. É um mundo intersubjetivo, “como sendo para qualquer um [...] E, contudo, cada um tem suas experiências" (Husserl, p.134, s/d).

A percepção do aí-para-mim do outro me é dada no ato da intropatia ${ }^{14}$ (Einfühlung), em que percebo o outro como igual, enquanto corpo-vivente que sente, percebe, raciocina, julga e se expressa. Esse é um ato que também "funda uma teoria transcendental do mundo objetivo, e seguramente em todos os aspectos, particularmente também a respeito da Natureza objectiva" (Husserl, p. 134, s/d). A percepção do corpo-vivente do outro que está ali para mim em sua concretude e, ao percebê-lo como igual a mim, em um ato perceptivo, portanto que ocorre no agora, compreendo-me como sendo um corpo-vivente que está ali, para ele. A concretude do corpo-vivente, espaço-temporalmente situado, a percepção que tem de si como eu-mesmo e que vai se constituindo no entrelaçamento de sentidos e de vivências de que se dá conta, é nuclear para a compreensão de si como estando "aqui e agora". Quando percebe o outro, que não ele, que está fora de si como um corpo-vivente, que se apresenta também em sua concretude e intencionalidades, não se dá um desdobramento dele (eu mesmo) no outro. Porém, a característica de o corpo-vivente do outro ser espaço-temporal abre a percepção de que ele está ali. Mais do que isso, pela reflexão dá-se conta que para o outro, ele (o eu-mesmo) está ali, ou seja, no seu aqui. Isso quer dizer que cada corpo-próprio percebe-se no seu aqui e no outro, como estando ali. Em termos ontológicos, o igual e o diferente convivem.

Ales Bello (2000, p. 160) afirma que atos de intropatia "se tratam de atos experienciais sui generis que E. Stein analisa, servindo-se, por vezes, de exemplos tirados de nossa vida quotidiana [...] ao ver ou encontrar alguém, às vezes chego a compreender os sentimentos que está vivenciando, isto é, se está sentido alegria ou dor. Certamente não estou sentindo a sua alegria ou sua dor, mas tenho uma experiência vivencial, um Erlebnis [...]". Pelo ato da intropatia, nos é dado a compreender a natureza da experiência do outro e, mais do que isso, "Husserl está indubitavelmente certo que essencial a essa experiência é minha consciência não apenas de que as outras pessoas são conscientes, mas também que sua consciência não é

\footnotetext{
${ }^{14}$ Será explicitada logo abaixo, neste tópico.
} 
diretamente acessível a mim" (Bell, 1990, p. 220). Essa questão não se torna um problema filosófico, mas, ao contrário, assegura que eu sou diferente do outro, uma vez que se "fosse esse o caso, se o que é próprio e essencial ao outro me estivesse disponível de um modo direto, então o outro seria apenas um momento de minha essência própria e, em conclusão, ele eu seríamos o mesmo" (Husserl, p. 148, s/d).

Portanto, os estados conscientes do outro não me são originalmente dados. Eu intuo, intropaticamente, que o outro é semelhante a mim; confirmo que é outro pela concretude do corpo-encarnado; intuo que sente como eu, pois posso perceber seus sentimentos (alegria, tristeza...), mas não sei como ele sente.

Fenomenologicamente, entende-se que é preciso que eu me perceba "ego" e ao outro "alter-ego", dando sustentação existencial às relações sociais. Eu, sujeito encarnado, tenho experiência do mundo que me é alheio e o percebo nas ações que realizo, nas minhas sensações táteis, visuais, e outras, bem como na cinestesia implícita ao eu faço, eu ando, eu posso. É um mundo intersubjetivo, "como sendo para qualquer um [...] E, contudo, cada um tem suas experiências" (Husserl, p.134, s/d). A percepção do aí-para-mim do outro me é dada pelo ato da intropatia (Einfühlung), que nos mostra o outro como igual, enquanto corpo-vivente que sente, percebe, raciocina, julga e se expressa. Esse é um ato que também "funda uma teoria transcendental do mundo objetivo, e seguramente em todos os aspectos, particularmente também a respeito da Natureza objectiva" (Husserl, p. 134, s/d). A percepção do corpo-vivente do outro que está ali para mim em sua concretude e, ao percebê-lo como igual a mim, em um ato perceptivo, portanto que ocorre no agora, compreendo-me como sendo um corpo-vivente que está ali, para ele.

Transcendemos a esfera da subjetividade e adentramos, pela intropatia, a esfera da intersubjetivade. Esta também é descrita, fenomenologicamente, nos modos de sua constituição inter-sujeitos. Husserl descreve o modo pelo qual percebe as próprias vivências, as do eu mesmo, consciente de si e de suas ações, bem como experiencia o mundo e nele o outro.

Em todo o caso, portanto, em mim, no quadro de minha vida de consciência transcendentalmente reduzida, tenho a experiência do mundo, incluindo os outros, e, segundo o sentido da experiência, não como formação sintética da minha privada, por assim dizer, mas antes como um mundo que me é alheio, como um mundo intersubjetivo, como sendo para qualquer um, como um mundo accesível para qualquer um nos seus objetos. E, contudo, cada um tem as suas experiências [...] (Husserl, p. 133, s/d) 
Como saber do modo pelo qual o outro sente, raciocina compreende o que não é ele mesmo, se a consciência do outro não me é dada originalmente? Pela expressão do que sente e compreende. Ou seja, pela linguagem. Assim, intropatia e linguagem são constitutivas da intersubjetividade. Isso mostra o sentido que o mundo intersubjetivo faz para o sujeito, sendo constituído pelos atos que vivencia em seu corpo-vivente. Enfatizo: não estou afirmando que o mundo intersubjetivo só passa a existir com o sujeito e suas vivências. Ao contrário, estou destacando que o existente no mundo-vida, na dimensão intersubjetiva, portanto também social da sociedade, não é internalizado ${ }^{15}$ ou introjetado ${ }^{16}$ pela pessoa, mas que esta, em sua subjetividade, constitui o conhecimento do outro e do social, não de modo solipsista, porém ao estar sempre no mundo-vida com os outros. No entanto, é ela que realiza os atos conscientes disparados pela intencionalidade.

\section{Objetividade do mundo}

Com a linguagem, expressando o sentido compreendido pelo sujeito, avançamos para a constituição da objetividade do mundo-vida, em que se convive com o outro. Ao mesmo tempo, também podemos visualizar o processo de produção de conhecimento que, uma vez produzido, torna-se passível de ser compartilhado histórica e culturalmente e reativado por um sujeito que, intencionalmente, a ele se dirige.

A produção do conhecimento é decorrente do movimento de materialização do sentido, percebido pelo sujeito, bem como das sínteses articuladoras que realiza e do esforço para expressá-las. Busca por modos de expressão que façam sentido para ele, que possam corresponder às suas intuições e evidências, ao se valer também de linguagens já postas no

\footnotetext{
${ }^{15}$ Internalização: em sociologia e outras ciências sociais (autores como John Finley Scott e George Herbert Mead trabalham com a explicação desse conceito). Significa a aceitação de um indivíduo de um conjunto de normas e valores (estabelecidos por outros) através da socialização. Internalizar é um processo que, mediante modos de interação entre pessoas, atitudes ou comportamentos tornam-se parte da natureza da pessoa por aprendizagem ou assimilação inconsciente: as pessoas aprendem estereótipos de gênero e os internalizam. Através da internalização, os indivíduos aceitam um conjunto de normas e valores que são estabelecidos por outros indivíduos, grupos ou sociedade como um todo. Bronfenbrenner (1971) traz um estudo sobre o processo de internalização por meio de práticas de relacionamento que conduzem à obediência e esta à auto-disciplina, internalizando os valores implícitos àquelas práticas. Bernstein (1974) traz estudos sobre sociologia da linguagem, explicando o processo de internalização ao tratar de temas como classe social, códigos de linguagem e elementos gramaticais, por exemplo. Lev Vygotsky fornece uma definição alternativa para a internalização, mediante a reconstrução interna de uma operação externa. Ele explica três etapas da internalização.

${ }^{16}$ Introjeção designa em psicologia e, mais especificamente, na teoria psicanalítica processo por meio do qual uma pessoa absorve, como parte integrante do ego, objetos e qualidades inerentes a esses objetos; interiorização. Na teoria psicanalítica, a introjeção desempenha um importante papel na formação do superego.
} 
mundo-vida, que habita com os outros e à medida que o expresso faz sentido para o outro que também com ele compartilha o mundo-vida, e que há uma aceitação do expresso (falado ou realizado por outra linguagem qualquer que seja) pelos sujeitos que estão juntos. Consuma-se, então, um ato objetivante que se torna passível de ser transmitido e retomado quer seja ao modo de repetição do compreendido ou mesmo pela prática da aplicação do compreendido. A expressão que ocorre pela linguagem proposicional vai além, uma vez que abre possibilidades e efetiva a organização lógica do expresso. Torna-se possível a efetivação da lógica formal e transcendental.

O dito nas palavras articuladas, de modo lógico, na gramática é passível de ser encadeado em uma cadeia de inferências. A escrita do dito assim organizado, retida em seus signos passíveis de serem decifrados, permite que a consciência intencional avance em deduções e inferências, transcendendo o então compreendido, bem como retroagindo, a partir do dado no presente (por exemplo, em um texto disponível), às evidências primeiras que se encontram na articulação do exposto. É destacável a compreensão expressa por Husserl em "A Origem da Geometria" sobre as possibilidades que se abrem frente a uma produção que se mantém na tradição nos modos pelos quais veio sendo, culturalmente, repetida. Expõe que essa produção (ele a exemplifica com um texto de geometria) pode ser tomada de modo passivo pela pessoa que apenas a repete e a aplica sem questionar o que diz, qual o sentido, quais as evidências que lhe dão sustentação, e, ainda, de modo ativo. Esse movimento se dá quando a pessoa, intencionalmente, põe-se a puxar os fios de sua articulação para compreender os sentidos veiculados. Ele vai além, alertando que esses modos de tomar o produzido estão presentes nas ações de ensinar (geometria).

Desse modo, parece que, começando com as autoevidências primeiras, a genuinidade original se propaga através da cadeia de inferência lógica, não importa quão longa ela seja. Ela transcende a finitude individual e mesmo cultural e social, pois traz consigo a remoção de limites de nossa capacidade, indo em direção a um encadeamento infinito. Nisso está a idealização permitida pela lógica e, portanto, também pela linguagem. Aí se encontra a base do procedimento histórico que retroativamente interroga pela origem. Aí se encontram tanto a possibilidade de um pensamento genuíno que busca pela origem dos atos evidentes, quanto aquele de se permanecer sob o jugo do fascínio da linguagem, da lógica e da própria ciência, quando se fica no nível da repetição de suas fórmulas. (Bicudo, 2016, p. 41) 
Para compreender a objetividade do mundo, é preciso focar a complexidade do todo da obra filosófica que Husserl, evidencia desde sua primeira publicação. Ao compreender as perguntas por ele formuladas, as explicitações que as descrições fenomenológicas e respectivas reduções possibilitaram, avançamos para a compreensão do significado de Lebenswelt (mundovida) que, em suas últimas obras, é explicitado e assumido.

A intencionalidade do olhar do sujeito que se dirige ao outro e o percebe como igual e como diferente, mas sempre como outro corpo-vivente, pressupõe que o eu e o outro compartilham o mesmo ambiente. Isso porque, ambos os corpos-viventes (do sujeito que vê o outro e o do outro que é visto e, reciprocamente, que vê...) ocupam um lugar na espacialidade e temporalidade do mundo. Mundo esse que lhes é comum e que é mundo-vida, solo em que habitamos uns com os outros (pessoas, ideias, religiões, teorias, teorias e crenças políticas, natureza animada e inanimada). Desse modo, nós (eu e o outro) vivemos no mundo que é nosso, ou seja, compartilhado. Husserl realiza uma análise fenomenológica do Mundo-Vida no livro “Crise das Ciências Europeias Contemporâneas" (2008). Vê a ciência (um dos exemplos de conhecimento produzido) como sendo uma realização humana e que pressupõe o mundo-vida como solo das experiências vivenciadas pelo corpo-vivente. No §37, denominado “As estruturas mais formal-gerais do mundo da vida ${ }^{17}$ : coisa e mundo, por um lado, consciência da coisa, por outro" (p.156), ele assim se refere:

O mundo da vida é - na presentificação do que ficou repetidamente dito - para nós, os que nele vivemos despertos, existindo sempre já de antemão, o "solo" para toda a práxis, tanto teorética quanto extrateorética. Para nós, que somos despertos, sujeitos continuamente e de algum modo praticamente interessados, o mundo é pré-dado como horizonte, não por uma vez, ocasionalmente, mas sempre e necessariamente como campo universal de toda práxis efetiva e possível. A vida é permanentemente viver-na-certeza-do-mundo. (Husserl, 2008, p. 156).

O mundo-vida se configura como tendo um sistema de aparência idêntico para quando a ele estamos atentos. Mas esse não é o caso "onde existem objetos intencionais que estão presentes para um ser e não para outros, não falamos de objetos físicos, do mundo real, mas sobre sonhos, imagens, alucinações, visões, fantasias, delírios, etc.” (Bell, 1990, p. 227). Husserl assume isso, confirmando que o mundo tem existência por haver uma percepção harmoniosa do

\footnotetext{
${ }^{17}$ Eu traduzo Lebenswelt por mundo-vida diferentemente da maioria dos autores da língua latina, que o traduzem como mundo da vida. Isso porque entendo que a vida é que constitui o mundo. Na nossa realidade mundana, a vida, em seus diferentes modos de se dar, é (sendo), à medida que os seres vivem expondo-se e tecendo essa realidade.
} 
seu todo.

Nos seus últimos trabalhos, Husserl reconhece a presença da prática da vida diária vivida em comunidade, a cultura, a história como constitutivos do mundo-vida.

O mundo-vida compartilhado pelos membros de uma dada sociedade, o ambiente em que eles se assumem habitando, é essencialmente um reflexo da cultura que têm em comum. Mas essa cultura ou civilização é primariamente manifesta nas disposições dos indivíduos e instituições ás quais pertencem [...] (Bell, 1990, p. 229).

Conforme suas exposições, Husserl compreende a cultura como um fenômeno histórico. Para ele, história “[...] não é, de antemão, outra coisa senão o movimento vivo da comunidade e da coinclusão da formação e da sedimentação originárias de sentido. (Husserl, Anexo III ao § $9^{a}, 2008$, p. 388)".

O fenômeno histórico enquanto tal é, aprioristicamente, dado ao sujeito que vem ao mundo. Essa sua constatação apontada por seus estudos o preocupam e, novamente, em "A Origem da Geometria" retoma o significado do a priori para a história factual, para explicitar que recorre a uma evidência incondicionada, que vai além de todas as facticidades históricas, uma evidência efetivamente apodíctica. Afirma:

O que, em si, é historicamente o primeiro, é o nosso presente. Sabemos sempre do nosso mundo presente, e sabemos que nele, vivemos cercados sempre por um horizonte infinito e aberto de efetividades desconhecidas. Este saber, como certeza de um horizonte, não é algo de aprendido, um saber que tenha sido alguma vez actual e que somente se tenha tornado imerso como um pano de fundo; a certeza do horizonte tinha já de ser pressuposta, para poder ser explicitada tematicamente, e já pressuposta para que se queira saber aquilo que ainda não se queira saber aquilo que ainda não se sabe. (Husserl, E., Anexo III ao § 9 a, 2008, p. 391-2).

Alguns autores veem paradoxos na afirmação de Husserl de que a história é um apriori. Carr (1970), por exemplo,

Carr argumenta que se levarmos a sério o pré-dado do mundo-vida, então o idealismo inicial de Husserl parece estar em dificuldade. Diz ainda que, embora o conhecimento teorético possa depender da consciência para sua constituição, o mundo-vida parece prover o material dado com o qual a consciência lida. Se, por outro lado, argumenta Carr, Husserl trata da constituição transcendental, como ele mesmo insiste, então na descrição do mundo-vida se perde o que estava escrito como aspecto essencial - seu ser dado como tal. Porém, ainda seguindo a 
argumentação desse autor, em ambos os casos surge uma segunda dificuldade: a tentativa de descrever o mundo-vida como uma atividade teorética, uma teoria fenomenológica de ordem mais elevada. Continuando, argumenta: mas, se toda atividade teorética pressupõe a estrutura do mundo-vida, então isso deve valer também para a fenomenologia que, nesse caso, não poderia dar-se sem pressupostos. E David Carr termina dizendo: Husserl precisa mostrar que a fenomenologia pode efetuar o telos de toda teoria sem ser "pega" em sua "arché". (Bicudo, 2016, p. 45)

Para dar um fechamento sobre minha compreensão do a priori do mundo-vida, como cultural e histórico, trago uma longa citação extraída do artigo acima (Bicudo, 2016) .

Não vejo esses paradoxos na fenomenologia husserliana como um todo e, especificamente, no que concerne à história e à historicidade.

Entendo que o mundo-vida é o mundo já dado e que compreende toda a formação histórica e deve ser interrogado, voltando-se à subjetividade e à intersubjetividade para que se compreenda como nascem os produtos culturais que caracterizam tal mundo. Ele provê o material e o faz de dois modos: como pré-predicativo e como pré-teorético. Pré-predicativo, pois é o mundo da experiência imediata. Pré-teorético, pois nesse mundo já é dada a comunidade, e com ela a linguagem de modo ingênuo. Compete à atitude fenomenológica colocar ambos em evidência, analisar e refletir sobre o material enlaçado no noesis-noema. Esse procedimento é fenomenológico. Não ignora o pré-dado, mas o enlaça. Ao trabalhar com o pré-predicativo dá conta da constituição do objeto pelo sujeito, da visada da ciência natural e da visada da fenomenologia. Ao trabalhar com o pré-teorético, dá conta do formal da ciência exata formal.

Aponto, ainda, a ponderação de Derrida assim expressa:

E, ao contrário do que a fenomenologia - que é sempre fenomenologia da percepção - tentou nos fazer acreditar, ao contrário do que nosso desejo não pode deixar de ser tentado a crer, a própria coisa se esquiva sempre (Derrida, 1994, p.117).

Não entendo como esse autor. Compreendo que a fenomenologia é sempre fenomenologia da percepção, pois seu princípio é o presente, a vivência do agora a qual engendra toda produção de nossas concepções de mundo. E Husserl sempre se preocupou com o fenômeno, com o que se mostra nessa vivência. A coisa sempre foi anunciada na fenomenologia husserliana como se mostrando e se constituindo para nós, seres humanos, por perfis e por indícios. Dai que ela nunca nos foi prometida como possibilidade de nós a 
apreendermos e a mantermos e mantermo-nos com segurança. A terra prometida, na filosofia de Husserl, não é a da segurança, mas a do sentido que o mundo que faz para nós possibilidade de nós a apreendermos e a mantermos e mantermo-nos com segurança. A terra prometida, na filosofia de Husserl, não é a da segurança, mas a do sentido que o mundo que faz para nós.

Esse meu entendimento do sentido da fenomenologia leva-me a refletir sobre o mundo e sobre nossa presença nele, bem como, sobre o nosso modo de viver e nossa própria vida.

O presente vivenciado no agora de nossa percepção nos dá evidências da verdade ${ }^{18}$ que dura apenas nesse instante e é obscurecido, necessitando ser reativado. Permanece nos limites do ego: se não for retomado de modo intencional, buscando pelo sentido e expressando o compreendido pela linguagem; se não for compartilhado com o outro. Porém o "outro" há que fazer sentido para aquele ego solipsista. Sempre na dimensão dos atos do corpo-vivente, o ato por ele atualizado, o de intropatia, o lança para fora da esfera solipsista, abrindo-lhe a dimensão do "nós". Intropatia que está na origem da compreensão do outro como igual e como diferente, pois o outro sempre é corpo-encarnado. Linguagem que diz, expressa o compreendido passível de ser também compreendido pelo outro, que habita o mesmo solo do mundo-vida. Mundo-vida que é movimento que presentifica a historicidade da cultura, portanto dos hábitos, das crenças, das atividades práticas do cotidiano, da ética de uma comunidade. Linguagem que possibilita a materialização do conhecimento, inclusive do da ciência e que, uma vez produzido, aí está também no mundo-vida para ser compreendido. Porém por mais rigoroso e exato que sejam os procedimentos de sua constituição e de sua produção, não nos dá certeza e segurança. Vivemos a certeza do agora, do instante presente que, como Kundera nos aponta, indica a “insustentável leveza do ser". (1984)

Entendo que a compreensão do sentido da fenomenologia nos abre caminhos para vislumbrar possibilidades de realizar pesquisa fenomenológica em educação.

\section{EDUCAÇÃO}

Educação ou ação de educar. Visa ao processo de formação da pessoa. Formação essa que é complexa e abrange muitos aspectos da vida vivida no mundo-vida. Esse movimento é originado e mantido na preocupação característica do ato de cuidar. Cuidar para que o ser vivente seja e que se realize ou se atualize de certa forma ou em certa direção.

\footnotetext{
${ }^{18}$ Merleau-Ponty (1990) assim se expressa sobre essa verdade: verdade em estado nascente. Isso porque para compreensões articuladas, logicamente, há todo um caminho a ser percorrido pelos atos da consciência.
} 
Conduzir esse processo, na posição daquele que se educa e que educa, solicita uma compreensão do mundo e da vida. Conforme explicitado no item anterior que se dedica a trazer ao leitor, como uma pequena introdução, o pensar fenomenológico mundo é entendido como mundo-vida, solo em que habitamos, estando com os outros seres, vivendo. De acordo com Ales Bello,

não é certamente fácil dar uma definição da vida, mas indubitavelmente, é o fenômeno que mais intensamente atrai nossa atenção, porque "sentimos" o viver, mas gostaríamos também de saber qual o sentido do próprio viver (Ales Bello, 2001, p.22).

Vivemos. Temos vida "agora". O agora é fluido, momento que passa e com ele passa a vida nos modos pelos quais vivemos. A vida de cada um de nós, tomada em sua individualidade, é incerta. Mantermo-nos vivendo é uma responsabilidade que exige cuidado de si e do outro, viventes com os quais somos. A educação se dá no momento presente e traz consigo o futuro. Não é uma questão de "formar para o futuro", mas sim de estar-se formando e formando no agora com o outro, na intersubjetividade que caracteriza o "nós" do mundo-vida entendido como cultural e histórico. Assumir essa postura - fenomenológica - nas ações educadoras traz consigo a responsabilidade ética para com a própria vida, com a vida do outro, seres humanos ou não, pois o mundo-vida é harmônico e as ações dos viventes geram forças e nutrem-se mutuamente.

No ambiente da escola, ou de outra instituição que visa educar, convivemos com o outro, sujeito-encarnado, portanto uma totalidade física, psíquica e espiritual.

Sendo o aluno um corpo-vivente, de imediato, ele se dá a ver em sua corporalidade e em suas ações. Do mesmo modo, ele assim vê, de imediato, também o outro (colegas e professor). Há uma reciprocidade que se estabelece entre eles. A intropatia o lança à percepção do outro como igual e como diferente. A linguagem - qualquer que seja - expressa sensações, percepções, afetividades, compreensões. Entendo que esse dado (ser corpo-vivente) abre horizonte para as ações educacionais que visam a ir além do ensino, direcionando-se para a formação da pessoa, do cidadão, da comunidade, da organização social, do Estado. A percepção do igual e do diferente ocorre de modo imediato, não necessitando de uma teoria a respeito de sermos iguais, porque humanos, impondo-se e apontando deveres e modos de tratar o diferente. Sim, somos diferentes. É preciso que deixemos nossa percepção avançar em conhecimento de nós mesmos e do outro. Não somos melhores, nem piores, mas diferentes. Em quê? Como? Ao mesmo tempo, somos iguais. Em quê? Como? 
A ação pedagógica nutre a ação de ensinar, realizada pelo professor de qualquer disciplina. Isso porque, ao ensinar se está assumindo valores, modos de estar com o outro e com o conhecimento, foco do ensino, os quais carregam consigo a visão de Educação. Entendo que o fazer pedagógico dispara na própria ação desencadeando a aprendizagem do que está sendo ensinado. Conforme exposto em (Baier \& Bicudo, 2020), o fazer pedagógico traz consigo tanto as ações cognitivas, como as mensagens percebidas nas atitudes assumidas por quem está educando/ensinando. Quando o pedagógico está unido à ação de educar, ele se direciona para uma meta, definida pelo desejo de promoção do modo de ser e de vir a ser do outro, de nós mesmos, de um povo. Esse desejo percorre toda uma gama de fins próximos e longínquos, pessoais e sociais. Carrega visões de mundo e de bem-estar da pessoa, da comunidade, da sociedade que dizem de ideais histórico-culturais de uma cultura e, de modo mais amplo, da humanidade. Sendo assim, imprime uma direção ao acontecer que se dá junto ao ensino e à educação.

Essa visão expõe a responsabilidade ética da ação de formar pessoas, ensinando. Como compreender a pessoa? É sinônimo de corpo-vivente? Este é uma totalidade física, psíquica e espiritual, visão essa decorrente de uma análise fenomenológica realizada por Husserl e por sua discípula Edith Stein, sobre a estrutura da pessoa. Porém além desses aspectos, o corpo-vivente também é constituído por um núcleo que marca sua singularidade. O núcleo é um elemento profundo, no sentido de estar nas profundezas da pessoa e não é dado na imediatez da percepção, como ocorre com a do corpo-encarnado. Conforme Ales Bello (2015, p. 83), o núcleo elemento último profundo - representa aquilo que diz respeito às características, absolutamente, singulares. Esse núcleo identitário não se desenvolve, mas dá a direção, como se indicasse a estrada ao espírito e à psique. Se soubermos identificar a estrada indicada, haverá possibilidade de seguir o próprio princípio de identidade pessoal. Para melhor esclarecer essa ideia, trago um excerto da obra de Edith Stein, Essere finito e Essere eterno, citado em Ales Bello (2015, p. 8283):

Sabemos que o estado psíquico momentâneo de uma pessoa não depende somente de sua história de vida e das condições presentes, mas é também determinado pelo núcleo de personalidade, ou seja, aquela consistência imutável de seu ser que não é resultado do desenvolvimento, mas pelo contrário impõe um certo andamento. É preciso ter consciência também desse núcleo quando devemos prever um estado psíquico. E quando se trata de 
determinar uma atividade futura, é preciso tomar em consideração, como um fator específico, também a vontade, porque vimos que esta não pode ser deduzida somente da força vital ou dos motivos.

O núcleo identitário é apenas princípio. Não é a vontade. No processo de formação, cuidamos da atualização da potência de ser da pessoa, cuja estrutura é dada na carnalidade do corpo-próprio e que vale para todos, podendo ser trabalhadas mediante atividades apropriadas. Estas estão no foco das atividades educacionais e são realizadas no solo do mundo-vida em que se está com o outro. Entretanto, cada pessoa é uma totalidade, enquanto ser singular.

Essa é a visão de educação que assumo e que, conforme entendo, está coerente com a filosofia fenomenológica. Permite: situar-me e ao educando, bem como o que é trabalhado (a disciplina que disponibiliza conteúdos a serem trabalhados) no aqui e agora, no mundo-vida, sendo com os outros; trabalhar o conhecimento nas dimensões da constituição e da produção, abrindo horizonte para possibilidades de trabalhar atividades que incidem nas sensações e na percepção do aluno, naquelas que se dedicam aos modos de expressar e de ficar atento ao entendimento do outro, ouvindo-o em suas manifestações e, ao mesmo tempo, respeitando-o como igual e como diferente e, da mesma forma, trabalhar com atividades que visam ao conhecimento já produzido e que são apresentados em textos escritos, pintura, música, imagens, dramas encenados, cultos religiosos, discursos políticos, propagandas, etc.; trabalhar a ética que se estabelece nos modos de estar com o outro; trazer à cena questões da vida e dos seus sentidos.

No parágrafo anterior, dediquei-me a trazer um panorama das atividades educacionais que visualizo possíveis e desejáveis e que entendo passíveis de serem realizadas, em suas maneiras apropriadas, com qualquer pessoa, de qualquer idade, em qualquer disciplina ou situação de formação.

\section{PESQUISA}

A investigação que procede de modo fenomenológico é sempre qualitativa, uma vez que o foco para se conhecer o outro e a si mesmo é a vivência. Portanto, o presente de sua realização. Como foi explicitada nos itens anteriores, a vivência se dá no corpo-encarnado e no agora, percebida em sua imediaticidade. O “agora”, momento instantâneo do acontecimento, desliza para o já foi. Sendo assim, é preciso retomá-la, vivificando-a, no fluxo da lembrança (Barbariz, 2017), podendo ser expressa apenas pela linguagem. Estamos nos referindo aqui do modo pelo qual o fenômeno é vivenciado e se mostra. Entende-se, portanto, que o mundo-vida (e tudo que 
abrange, inclusive o si-mesmo) é dado nas vivências do corpo-encarnado e vem a ser explicitado pela linguagem, em suas diferentes possibilidades de expressão.

É nesse entendimento que se encontra a importância da descrição em investigações qualitativas fenomenológicas. É um modo de ir à coisa, ela mesma, porém entendendo que ao nos referirmos a ela, já nos afastamos dela. E, mais do que isso. Valemo-nos de intermediário: a linguagem que veicula o vivenciado e compreendido no movimento de constituição do conhecimento.

Antes de focar as questões filosóficas implicadas no estudo da linguagem, vou expor como vejo o encontro da filosofia fenomenológica com a investigação do mundo da educação e o rigor do pesquisador para realizar uma investigação.

O ambiente da educação é subjetivo e também intersubjetivo e objetivo, como todo solo do mundo-vida em que habitamos. As atividades realizadas pelo aluno permitem que estudemos fenômenos situados que interrogamos. Por exemplo, como o aluno de 4/5 anos que reside em tal lugar e frequenta tal escola aprende a se posicionar na espacialidade, constituindo conhecimento geométrico? Detoni (2000) realizou uma investigação que mostra como procedeu e compreendeu esse fenômeno. Note-se que, nessa pesquisa, não se parte de a prioris teóricos sobre aprendizagem, espaço, ideias geométricas. Mas se busca aquele que vivencia o fenômeno. Foram realizados e filmados encontros. Os filmes foram transcritos e analisados. Quero enfatizar que o rigor, baseado no cuidado do movimento da investigação, advém de estar atento à interrogação formulada. Esse rigor também solicita que seja explicitado o que se busca saber. Para tanto, realiza-se um exercício investigativo para esclarecer o que é perguntado, ficando-se atento às maneiras visualizadas de isso que se quer saber ser se mostrar. Perguntamo-nos: Como? Quais seriam os caminhos possíveis? Esse momento é o de investigar aonde ir, buscar pelos sujeitos significativos, ou seja os que vivenciam o fenômeno interrogado ou que explicitam, ao modo de conhecimento produzido, o que compreendeu dele. Neste último caso, são pesquisas que incidem sobre obras de autores (livros, filmes, arquitetura, etc.). Cada passo dado, que evidencia a escolha, há que ser explicitado como e por que foi dado desse modo. A escolha não é casual; não é também baseada em teoria da estatística que trabalha com probabilidade de acontecimentos. É analisada e refletida pelo pesquisador com seu grupo de pesquisa, ouvindo o que é dito na comunidade que trabalha com o assunto investigado.

Voltando à questão da linguagem que diz do compreendido. Apenas para evidenciar a 
dificuldade da pesquisa, vou focar, como exemplo, a descrição realizada em duas modalidades de linguagem: a escrita e a filmada.

O pesquisador pode gravar entrevistas. O sujeito entrevistado há que ser significativo. A entrevista não segue um questionário pré-elaborado, pois, neste caso, o pesquisador estaria direcionando o dito pelo entrevistado e partindo de a prioris. Há sim uma interrogação: a do pesquisador. Esta é transformada em pergunta disparadora da entrevista que, para ser realizada e gravada, há que haver concordância por escrito e assinada pelo entrevistado. Deve acontecer ao modo de um diálogo em que o pesquisador fique atento ao dito, ouvindo o exposto. Nesse ouvir, algumas pequenas intervenções podem ocorrer e cujo sentido se faz na realidade que está sendo vivenciada por ambos (pesquisador e entrevistado). Posteriormente, o pesquisador ouve muitas vezes a gravação até compreender o sentido do dito e passa a transcrevê-la, sem interpretações. Se a investigação não for documental, esse texto transcrito não retorna ao pesquisador, porque se busca estar o mais próximo possível de sua expressão primeira a respeito do perguntado.

A análise há que considerar a interrogação e o dito pelo sujeito significativo. E então uma dificuldade se evidencia. A linguagem falada é estruturada por palavras (que dizem) e pela gramática (que dá sustentação lógica à organização do veiculado pelas palavras). As palavras são polissêmicas. Carregam consigo sentidos de muitas vivências e de significados históricoculturais que vem sendo explicitados ao longo do tempo. Mas também a pessoa que fala, busca por palavras apropriadas ao que quer dizer de sua vivência. Estabelece-se uma sintonia e uma dissonância. Sintonia, pois o sujeito significativo busca pelas palavras que possam dizer o que compreende. Dissonância, porque a palavra diz menos e diz mais do que quer dizer, por trazer consigo a historicidade dos sentidos articulados e expressos. Além disso, a gramática organiza. Pausas no falar o que querem dizer? O sujeito está pensando? Buscando palavras? É uma vírgula ou ponto que separam ideias?

Essa análise não pode tomar a linguagem como objetivamente dada e repetir o dito como excerto da fala do sujeito, exemplificando o que pretende mostrar como possíveis compreensões da interrogação formulada.

No caso de a descrição de um acontecimento ser relatado por um filme, há que se adentrar pela linguagem fílmica: cenas, movimentos, olhares, intencionalidades expressas pelos personagens, luminosidade, profundidade e por aí vai. E há situações em que se filmam 
encontros com os sujeitos significativos e, neste caso, indico as investigações de Detoni (2000), de Marli (2013), Pinheiro (2018), como exemplos. Há casos em que se busca compreender o que um determinado filme diz.

Apenas descrever o fenômeno no modo pelo qual ele se dá a conhecer é importante para

a realização da investigação fenomenológica, mas dela não há como se dar conta. É preciso a análise de cada descrição (falas de sujeitos, cenas de filmes) e realizar movimento de articulação das ideias compreendidas, bem como buscar convergências de ideias em ideias mais abrangentes, fortes no que trazem. Abre-se, então, para a interpretação das reduções que conduzem à compreensão das ideias abrangentes. Em Bicudo (2011), há a explicitação de modos de proceder em pesquisa qualitativa fenomenológica, conforme entendo. Exemplos desses procedimentos também são expostos nas teses e nas dissertações que oriento e que se encontram no site www.maricabicudo.com.br.

\section{Dificuldades}

Dificuldades de proceder à pesquisa desse modo? Muitas; ao mesmo tempo fáceis e difíceis de serem enfrentadas. Elas se encontram na mudança do olhar do pesquisador que deixa de olhar o mundo e suas coisas e objetos de modo natural, e passa a vê-los pelo olhar fenomenológico, assumindo que "da coisa" ou "da verdade última" não se pode dar conta e que sempre se vive no presente. A verdade absoluta, a nós humanos, não nos é dada, assim como não nos é dada a certeza de mantermo-nos vivos. Entretanto, enquanto pesquisador e educador responsável precisamos permanecer atentos e perseguir o rigor. É nessa mudança do olhar ou de visada que se aloja a dificuldade, pois trazemos impregnada a visão dominante da ciência do mundo ocidental, bem como do seu ideário; tomamos o real como objetivamente observável e visamos a certeza.

\section{DANDO CONTA DO TÍTULO}

Dei conta? Apenas os leitores podem responder.

\section{Referências}

Ales Bello, A. (2000). A Fenomenologia do Ser Humano. $1^{\mathrm{a}}$ edição. Bauru: EDUSC.

Ales Bello, A. (2016). Fenomenologia-Psicopatologia-Neurociências: e a Consciência? In M.A.V. Bicudo \& A.E.A. Antúnez (Org.), Fenomenologia, psicopatologia e neurociências: e a consciência? (p. 54-114). São Paulo: Universidade de São Paulo. 
Ales Bello, Angela. (2001). “A formação da pessoa” In: Bicudo, M.A.B. \& Belluzzo, R.C.B. (Orgs.). Formação Humana e Educação. Bauru: EDUSC.

Ales Bello, Angela. (2015). Pessoa e Comunidade. Comentários: Psicologia e Ciências do Espírito de Edith Stein. Belo Horizonte: Ed. Artesã.

Baier, T. \& Bicudo, M.A.V. "mathematics in african cultural creations: open horizons to the world of mathematics education and the formation of the person." In Bicudo, M.A.V. (2020). Constitituion and Production of Mathematics in the Cyberspace. Cham, Switzerland: Springer International Publishing.

Barbariz, T.A.M. (2017). A constituição do conhecimento matemático em um curso de matemática à distância. Tese de Doutorado, Instituto de Geociências e Ciências Exatas. Universidade Estadual Paulista "Júlio de Mesquita Filho". Rio Claro

Bernstein, Basil. (1975). Class, Codes and Control: theoretical studies towards a Sociology of Language. (1st published by Schcken Books). New York: Schoken Books.

Bicudo, M.A.V. "Constituing mathematical knowledge being-with-media in cyberspace”. In Bicudo, M.A.V. (2020). Constitituion and production of mathematics in the cyberspace. Cham, Switzerland: Springer International Publishing.

Bicudo, Maria A.V. (1999). Fenomenologia: Confrontos e Avanços. São Paulo: Cortez Editora.

Bicudo, Maria A.V. (2011). Pesquisa Qualitativa: segundo uma visão fenomenológica. São Paulo: Cortez.

Bicudo, Maria A.V. (2016). Fenomenologia e Direito. Cadernos da EMARF, (v.9, n.1, p.1174, abr./set.). Rio de Janeiro.[s.n.]

Bondía, Jorge Larrosa. (2002). Notas sobre a experiência e o saber de experiência. Revista Brasileira de Educação, (19), 20-28. Disponible en: http://www.scielo.br/scielo.php?script=sci_arttext\&pid=S141324782002000100003\&lng=en\&nrm=iso. Accesado en: 03 May 2010 https://doi.org/10.1590/S1413-24782002000100003

Bronfenbrenner, Urie. (1971). Two Worlds of Childhood - USA and USSR. 1st edition. London: George Allen \& Unwin Ltd.

Carr, D. (1970). “Translator's Introduction.” In E. Husserl. The Crisis of European Sciences and Transcendental Phenomenology. $1^{a}$ edição. Evanston, Nothwestern University Press, p. XV - XLIII.

Derrida, J. (1994). A Voz e o Fenômeno. $1^{\mathrm{a}}$ edição. Rio de Janeiro: Jorge Zahar Editor, 117 p.

Detoni, A.R. (2000). Investigações acerca do espaço como um modo de existência e da geometria que ocorre no pré-reflexivo. Tese de Doutorado, Instituto de Geociências e Ciências Exatas. Universidade Estadual Paulista. Rio Claro.

Heidegger, Martin. (1992). Que é uma coisa? Trad. Carlos Morujão. Lisboa: Edições 70.

Husserl, E. (2008). $\$ 73$ Estudo da historicidade. Historicidade primeira. Anexo XXV ao $§ 73$. In E. Husserl. $1^{\text {a }}$ edição. A Crise das Ciências Europeias e a Fenomenologia Transcendental. Uma Introdução à Filosofia Fenomenológica. Trad. Diogo Falcão ferrer. Lisboa: Phainomenon e Centro de Filosofia da Universidade de Lisboa, p. 9 - 559. 
Husserl, E. (2002). Idee per una Fenomenologia pura e per uma filosofia fenomenológica. Trad. Enrico Filippini. Volume II. Torino: Einaudi.

Husserl, E. (2008). Anexo II ao §9a . In E. Husserl. $1^{\mathrm{a}}$ edição. A Crise das Ciências Europeias e a Fenomenologia Transcendental. Uma Introdução à Filosofia Fenomenológica. Trad. Diogo Falcão ferrer. Lisboa: Phainomenon e Centro de Filosofia da Universidade de Lisboa, p. $9-559$.

John Finley Scott '55 Reed Magazine. Reed College. Novembro de 2008. (Consultado em 26 de abril de 2016)

Kundera, Millan. (1984). A insustentável leveza do ser. $1^{a}$ edição. São Paulo: Companhia das Letras.

Mead, G.H. (1934). Mind, Self, Society. Chicago: Chicago University Press.

Merleau-Ponty, Maurice. (1990). O primado da Percepção. Campinas: Papirus.

Moura, C.A.R. de. (1999). Crítica da Razão na Fenomenologia. $1^{a}$ edição. São Paulo: EDUSP.

Pinheiro, J.M.L. (2018). O movimento e a percepção do movimento em ambientes de Geometria Dinâmica. Tese de Doutorado, Instituto de Geociências e Ciências Exatas - Universidade Estadual Paulista, Rio Claro.

Silva, Marli Regina. (2013). Um estudo fenomenológico sobre o conhecimento geométrico. Tese de Doutorado, Instituto de Geociências e Ciências Exatas - Universidade Estadual Paulista, Rio Claro.

São Paulo, 17 de maio de 2020. 